\title{
Novel bone microenvironment model of castration-resistant prostate cancer with chitosan fiber matrix and osteoblasts
}

\author{
MASAHIRO SAMOTO $^{1}$, HIDEYASU MATSUYAMA ${ }^{1}$, HIROAKI MATSUMOTO ${ }^{1}$, HIROSHI HIRATA ${ }^{1}$, \\ KOJI UENO ${ }^{2}$, SHO OZAWA ${ }^{1}$, JUNICHI MORI ${ }^{1}$, RYO INOUE ${ }^{1}$, SEIJI YANO ${ }^{1}$, YOSHIAKI YAMAMOTO ${ }^{1}$, \\ JUN HAGINAKA ${ }^{3}$, SHIZUYO HORIYAMA ${ }^{3}$ and KOJI TAMADA ${ }^{4}$ \\ ${ }^{1}$ Department of Urology and ${ }^{2}$ Center for Regenerative Medicine, Graduate School of Medicine, Yamaguchi University, \\ Ube, Yamaguchi 755-8505; ${ }^{3}$ School of Pharmacy and Pharmaceutical Sciences, Mukogawa Women's University, \\ Nishinomiya, Hyogo 663-8179; ${ }^{4}$ Department of Immunology, Graduate School of Medicine, \\ Yamaguchi University, Ube, Yamaguchi 755-8505, Japan
}

Received April 9, 2021; Accepted July 20, 2021

DOI: 10.3892/ol.2021.12950

\begin{abstract}
The interaction between prostate cancer cells and osteoblasts is essential for the development of bone metastasis. Previously, novel androgen receptor axis-targeted agents (ARATs) were approved for metastatic castration-naïve and non-metastatic castration-resistant prostate cancer (CRPC); both of which are pivotal for investigating the association between the bone microenvironment and tumors. The present study established a novel in vitro 3D microenvironment model that simulated the bone microenvironment of CRPC, and evaluated the drug susceptibility of ARATs and the efficacy of the combination of abiraterone and dutasteride. Green fluorescent protein-transferred C4-2 cells (a CRPC cell line) and red fluorescent protein-transferred human osteoblasts differentiated from human mesenchymal stem cells were co-cultured in chitosan nanofiber matrix-coated culture plates to simulate the 3D scaffold of the bone microenvironment. The growth of C4-2 was quantified using live-cell imaging and the Cell3 iMager duos analysis system. The growth of C4-2 colonies were quantified for a maximum of 30 days. The expression of TGF- $\beta$ increased and promoted EMT in C4-2 cells co-cultured with osteoblasts, indicating resistance to ARATs. The $\mathrm{IC}_{50}$ of each drug and the combination effect of abiraterone and dutasteride were evaluated using this model. Combination treatment with abiraterone and dutasteride synergistically inhibited the growth of C2-4 colonies compared with individual investigational agents. This could be attributed to the reduction of 3 -keto-5 $\alpha$-abiraterone, an androgen receptor agonist. The bone
\end{abstract}

Correspondence to: Dr Hideyasu Matsuyama, Department of Urology, Graduate School of Medicine, Yamaguchi University, 1-1-1 Minamikogushi, Ube, Yamaguchi 755-8505, Japan

E-mail: hidde@yamaguchi-u.ac.jp

Key words: bone metastasis, drug screening, osteoblast, prostate cancer, three-dimensional co-culture microenvironment model of the present study is unique and useful for evaluating new drug susceptibility testing in prostate cancer cells. This model may help to reveal the unknown mechanisms underlying micro- to clinical bone metastasis in prostate cancer.

\section{Introduction}

Prostate cancer is the most common non-cutaneous cancer in men and is a major health problem in developed countries. It is expected to emerge as a major health concern worldwide as the average human lifespan increases in developing countries (1). Prostate cancer is often characterized by asymptomatic slow growth and men with localized prostate cancer have a high (10-year) survival rate (2). Clinically localized prostate cancer is a potentially curative stage and is managed by radiation therapy or radical prostatectomy. However, disseminated tumor cells (cytokeratin-positive cells) were detected in bone marrow aspirates in $13 \%$ of patients who underwent radical prostatectomy, suggesting that potential bone metastasis develops during the early stages of cancer (3). In contrast to localized prostate cancer, men with metastatic prostate cancer have a poor survival rate, with a 5-year survival rate of $\sim 30 \%$ and a median survival rate of $\sim 3$ years $(4,5)$. In the locally advanced or metastatic stage, androgen deprivation therapy (ADT) is the mainstay of treatment and acts by decreasing the circulating testosterone levels. However, most patients eventually develop resistance to ADT and progress towards castration-resistant prostate cancer (CRPC) after 18-36 months (6,7). Among metastatic organs, bone is the most frequently metastatic site, and more than $90 \%$ of patients with advanced stage harbor bone metastases prior to 24 months of death (8). Bone metastasis deteriorates patients' quality of life by causing pain and making bones prone to fracture. Bone metastasis management based on understanding the developmental mechanisms is critical in prostate cancer patients, and a few in vitro models mimicking the bone microenvironment have been reported $(9,10)$. 
Recently, novel androgen receptor axis-targeted agents (ARATs) have been approved for metastatic castration-naïve prostate cancer (mCNPC) or non-metastatic castration-resistant prostate cancer (nmCRPC). The AR axis remains an essential player in CRPC and maximizes androgen deprivation by blocking AR function directly with competing antagonists of the cognate ligand DHT or by reducing intratumoral androgen synthesis with CYP17A1 lyase/hydrolase inhibitors. Abiraterone, a CYP17A1 lyase/hydrolase inhibitor, blocks androgen synthesis and prolongs survival in patients with CRPC (11). Abiraterone is metabolized by 3-beta-hydroxysteroid dehydrogenase 1 (3ßHSD1) to delta-4-abiraterone (D4A), which exerts the greatest antitumor activity among abiraterone and its metabolites. However, D4A is metabolized by $5 \alpha$-reductase to 3 -keto- $5 \alpha$ abiraterone, which possesses androgenic activity and stimulates prostate cancer progression. Recently, combination therapy based on abiraterone and dutasteride (a $5 \alpha$-reductase inhibitor) has garnered considerable attention as a CRPC treatment (12). Although dutasteride is approved for the treatment of BPH and regresses prostate volume by inhibiting dual $5 \alpha$-reductase (type 1 and 2 ), the risk reduction effect on the development of prostate cancer has been reported in the REDUCE trial (13). Combination therapy of abiraterone with dutasteride increases serum levels of D4A and reduces the levels of 3-keto-5 $\alpha$-abiraterone (12). However, the effects of these investigational agents, including D4A, on the bone microenvironment remain unclear, and elucidating them would be pivotal in investigating the association between the bone microenvironment and tumor. These observations led us to establish a new in vitro drug sensitivity testing model that accurately reflects the bone microenvironment.

In this study, we established a novel in vitro 3D microenvironment model that mimicked the bone microenvironment of CRPCs and examined whether it recapitulates the factors reported previously, including TGF- $\beta$. We used this model to evaluate the drug sensitivity of ARATs and the efficacy of the combination of abiraterone and dutasteride in the bone microenvironment.

\section{Materials and methods}

Cell culture. The human prostate cancer cell line LNCaP C4-2 (cat. no. CRL-3314) was purchased from the American Type Culture Collection. Human mesenchymal stem cells (hMSCs; cat. no. C-12974) from the bone marrow were obtained from PromoCell. The C4-2 cells were routinely grown in RPMI-1640 medium (Life Technologies) supplemented with $10 \%$ fetal bovine serum (FBS; Invitrogen; Thermo Fisher Scientific, Inc.), hMSCs were cultured in Mesenchymal Stem Cell Growth Medium 2 (cat. no. C-28009; PromoCell) and maintained in humidified incubators $\left(5 \% \mathrm{CO}_{2}\right)$. Penicillin $\mathrm{G}$ $\left(100 \mathrm{U} \cdot \mathrm{ml}^{-1}\right)$ and streptomycin sulfate $\left(0.1 \mathrm{mg} \cdot \mathrm{ml}^{-1}\right)$ (cat. no. A5955; Sigma-Aldrich; Merck KGaA) were added to all conditioned media.

Transfection of fluorophores. To quantify cell dynamics non-invasively, fluorescent proteins (GFP and RFP) were introduced into the cells. The GFP gene was introduced into C4-2 cells and the RFP gene was introduced into
hMSCs using lentivirus. C4-2 cells were incubated in RPMI-1640 medium supplemented with 10\% FBS in a $10-\mathrm{cm}$ dish and hMSCs were incubated in Mesenchymal Stem Cell Growth Medium 2 in a 10-cm dish. C4-2 cells were transfected with $6 \mu \mathrm{g}$ of BLIV 2.0 Reporter: MSCV -Luciferase-EF1 $\alpha$-copGFP-T2A-Puro Lentivector Plasmid (cat. no. BLIV713PA-1; System Biosciences, LLC) and hMSCs were transfected with $6 \mu \mathrm{g}$ of BLIV 2.0 Reporter: pCDH-CMV-MCS-EF1-RFP-T2A-Puro (cat. no. CD516B-2, System Biosciences, LLC) and $4 \mu \mathrm{g}$ of pPACKH1 HIV Lentivector Packaging Kit (cat. no. LV500A-1; System Biosciences, LLC) using X-tremeGENE HP DNA Transfection Reagent (cat. no. 6366244001; Roche). After overnight incubation, the medium was replaced with fresh medium and the cells were incubated for 3 days. The medium was transferred to a $15 \mathrm{ml}$ tube, followed by centrifugation at 3,000 rpm for $5 \mathrm{~min}$, and the supernatant containing lentiviral particles was passed through a syringe filter (cat. no. SLPES2545S; Hawach Scientific). C4-2 cells were incubated for 3 days in RPMI-1640 medium supplemented with $10 \%$ FBS containing lentiviral particles and polybrene (8 $\mu \mathrm{g} / \mathrm{ml}$; cat. no. H9268; Sigma-Aldrich; Merck KGaA). hMSCs were incubated for 3 days in Mesenchymal Stem Cell Growth Medium 2 containing lentiviral particles and polybrene. Since the downstream region of the plasmid contains a puromycin resistance gene, GFP-expressing or RFP-expressing cells were selected using puromycin ( $1 \mathrm{mg} / \mathrm{ml}$; cat. no. A1113802; Thermo Fisher Scientific, Inc.).

Osteogenesis. To promote osteogenic differentiation, hMSCs were cultured in Mesenchymal Stem Cell Osteogenic Differentiation medium (cat. no. C-28013; PromoCell). The medium was changed every 3-4 days for 2 weeks. After differentiation, the cells were fixed with $10 \%$ formalin solution, stained with 1\% Alizarin Red S (cat. no. 5533-25G, Sigma-Aldrich) to confirm extracellular calcium deposits, and stained with BCIP/NBT (cat. no. B5655; Sigma-Aldrich; Merck KGaA) to confirm alkaline phosphatase activity.

Bone microenvironment model of prostate cancer in $3 D$ culture. RFP-transfected hMSCs were plated $\left(5 \times 10^{4}\right.$ cells $\left./ \mathrm{cm}^{2}\right)$ onto a chitosan nanofiber-coated culture plate (Hokkaido Soda Co., Ltd.) and incubated with Mesenchymal Stem Cell Growth Medium 2. When cells reached $100 \%$ confluency, the medium was changed to Mesenchymal Stem Cell Osteogenic Differentiation medium (Day 0), followed by 14 days of incubation to induce human osteoblasts. On day 14, GFP-transfected C4-2 cells $\left(1.5 \times 10^{3}\right.$ cells $\left./ \mathrm{cm}^{2}\right)$ were added and co-cultured with human osteoblasts. On day 15 , the medium was changed to androgen-free, phenol red-free RPMI-1640 medium (Life Technologies) supplemented with $5 \%$ charcoal/dextran-treated fetal bovine serum (HyClone). Penicillin G (100 U $\left.\cdot \mathrm{ml}^{-1}\right)$ and streptomycin sulfate $\left(0.1 \mathrm{mg} \cdot \mathrm{ml}^{-1}\right)$ were added to all conditioned media. The medium was changed every 3-4 days.

Quantification of C4-2 and osteoblast cells. The growth of C4-2 and osteoblasts in the bone microenvironment model was quantified using an imaging system, Cell ${ }^{3}$ iMager duos (SCREEN Holdings Co., Ltd.) every 3-days. The sum of the green or red intensity area of each well was determined using 
the $\mathrm{Cell}^{3}$ iMager duos software version 1.4 rev 2.1, (SCREEN Holdings Co., Ltd.).

Drug sensitivity test using bone microenvironment model. A total of four ARATs (enzalutamide, apalutamide, darolutamide, and abiraterone), D4A (abiraterone metabolite with AR antagonist) and dutasteride ( $5 \alpha$-reductase inhibitor) were selected for drug sensitivity testing using a microenvironment model. All drugs were purchased from Selleckchem. In the drug sensitivity test over time, each drug was added to the culture medium at a concentration of $5 \mu \mathrm{M}$ dissolved in ethanol from day 15 . The final concentration of ethanol in all the drugs and controls was $0.1 \%$. Investigational agents were added every time the medium was changed. In the dose-response curve, each drug was added to the culture medium at each concentration dissolved in ethanol on day 15 . The drug exposure time was $48 \mathrm{~h}$, and the antiproliferative effect of the drug on C4-2 cells was determined by comparison with the concentration at $0.01 \mu \mathrm{M}$ of each drug. CompuSyn software was used to calculate the combination index (CI) at several effective doses $(\mathrm{CI}=1$; additive effect, $\mathrm{CI}<1$; synergy effect, $\mathrm{CI}>1$; antagonistic effect) (14).

Total RNA extraction and quantitative mRNA expression analysis. Total RNA was extracted using the RNeasy Mini Kit (Qiagen), according to the manufacturer's protocol. RNA quality and quantity were determined using a NanoDrop Lite spectrophotometer (Thermo Fisher Scientific, Inc.). First-strand cDNA was synthesized from $1 \mu \mathrm{g}$ of total RNA using the $\mathrm{RT}^{2}$ First Strand Kit (Qiagen). RNA expression of EMT-related genes was analyzed using the $\mathrm{RT}^{2}$ Profiler PCR Array Human Epithelial to Mesenchymal Transition (EMT) (cat. no. PAHS-090ZA; Qiagen), and RNA expression of osteogenesis-related genes was analyzed using the $\mathrm{RT}^{2}$ Profiler PCR Array Human Osteogenesis (cat. no. PAHS-026Z, Qiagen). The expression of AR and PSA was analyzed using TaqMan Gene Expression Assays (Applied Biosystems Inc.). The TaqMan MGB probes used in this study were as follows: AR (Hs00171172_m1), PSA (Hs02576345_m1, GAPDH (Hs02758991_g1). Quantitative real-time PCR was performed in triplicate using Applied Biosystems StepOnePlus (Applied Biosystems) according to the manufacturer's protocol. RNA expression levels were determined using StepOnePlus software (version 2.2.2; Applied Biosystems) and normalized to GAPDH expression levels. The following thermocycling conditions were used: initial denaturation at $95^{\circ} \mathrm{C}$ for $20 \mathrm{sec}$, followed by 40 cycles at $95^{\circ} \mathrm{C}$ for $1 \mathrm{sec}$ and $60^{\circ} \mathrm{C}$ for $20 \mathrm{sec}$. RNA expression levels were determined using the $2^{-\Delta \Delta \mathrm{CT}}$ method (15).

Western blot analysis. Cell samples were collected in RIPA lysis buffer (Santa Cruz Biotechnology Inc.), and protein concentrations were determined using a BCA Protein Assay Kit (Takara Bio Inc.). Each lysate sample ( $20 \mu \mathrm{g})$ was separated by SDS-PAGE and electro-transferred to a polyvinylidene fluoride (PVDF) membrane. Following blocking with 5\% non-fat milk in TBS with $0.05 \%$ Tween-20 (TBST), the membranes were incubated with each primary antibody overnight at $4^{\circ} \mathrm{C}$. The primary antibodies used were as follows: N-cadherin (1/500 dilution, cat. no. 13116), E-cadherin (1/1,000 dilution, cat. no. 3195), Snail (1/1,000 dilution, cat. no. 3879), TGF- $\beta$ (1/1,000 dilution, cat. no. 3709), and GAPDH (1/2,000 dilution, cat. no. 5174), from Cell Signaling Technology. AR (1/1,000 dilution; cat. no. ab133273) from Abcam. After washing with TBST, the membranes were incubated with HRP-conjugated anti-rabbit IgG secondary antibody (1/5,000 dilution, cat. no. ab6721; Abcam) for $1 \mathrm{~h}$ at room temperature. After washing with TBST, membrane signals were detected using an ECL detection system (Amersham Imager 600; GE Healthcare Life Sciences). GAPDH was used for normalization of the protein bands.

Magnetic-activated cell sorting (MACS). Highly purified C4-2 cells were isolated from co-cultured cells using MACS ${ }^{\circledR}$ (Miltenyi Biotec), using positive selection. Co-cultured cells $\left(1 \times 10^{7}\right)$ were centrifuged $(200 \mathrm{x} \mathrm{g}$ for $4 \mathrm{~min})$ and then resuspended in $100 \mu \mathrm{l}$ of MACS buffer (PBS containing $2 \mathrm{mM}$ EDTA and $0.5 \%$ FBS). Biotin anti-human PSMA (FOLH1) antibody (10 $\mu 1$, cat. no. 342510; BioLegend) was added and incubated for $5 \mathrm{~min}$ at $4^{\circ} \mathrm{C}$. Cells were washed in $2 \mathrm{ml}$ of MACS buffer and centrifuged again at $200 \mathrm{x} \mathrm{g}$ for $4 \mathrm{~min}$. The cellular pellet was resuspended in $200 \mu \mathrm{l}$ of MACS buffer and $20 \mu \mathrm{l}$ of anti-biotin microbeads (Miltenyi Biotec). After incubation for $15 \mathrm{~min}$ at $4^{\circ} \mathrm{C}$, the cells were washed in $2 \mathrm{ml}$ of MACS buffer and centrifuged at $200 \mathrm{x} g$ for $4 \mathrm{~min}$. The cellular pellet was resuspended in $500 \mu 1$ of MACS buffer loaded onto an LS MACS column (Miltenyi Biotec) in a magnetic field. Pass-through (unlabeled) cells were collected, and the column was washed three times with $500 \mu \mathrm{l}$ of MACS buffer. The MACS column was removed from the magnetic stand, and PSMA-positive (labeled) cells were eluted with $5 \mathrm{ml}$ of MACS buffer. The PSMA-positive cells and pass-through cells were analyzed by flow cytometry.

Flow cytometryanalysis. Anallophycocyanin(APC)-conjugated anti-human PSMA (FOLH1) antibody (cat. no. 342508, BioLegend) was used in this study. Flow cytometric data were acquired using a CytoFLEX S System cell (Beckman Coulter) and analyzed using FlowJo software (FlowJo, LLC).

Liquid chromatography-electrospray ionizationtime-of-flight/mass spectrometry analysis. C4-2 cells and osteoblasts were co-cultured for $24 \mathrm{~h}$, and abiraterone alone or a combination of abiraterone and dutasteride were added to the culture medium at a concentration of $5 \mu \mathrm{M}$ dissolved in ethanol on day 15. Cell suspensions were collected on days 17 and 28 (2 and 13 days after drug addition), and C4-2 cells were isolated by MACS $^{\circledR}$ using an anti-PSMA antibody. C4-2 cells ( $1 \times 10^{5}$ cells) were washed with PBS by centrifugation at $200 \mathrm{x} \mathrm{g}$ for $5 \mathrm{~min}$. They were then washed twice under the same conditions. The cell pellets were lysed with $50 \mu \mathrm{l}$ of $70 \%$ acetonitrile and then centrifuged at $17,4000 \mathrm{x} \mathrm{g}$ for $5 \mathrm{~min}$ at $4^{\circ} \mathrm{C}$. The resulting supernatants were collected, diluted to $1 / 20$ with $80 \%$ methanol in water, and analyzed by liquid chromatography (LC)-electrospray ionization (ESI)-time-of-flight/mass spectrometery (TOF-MS). The LC system used was a Nexera SFC/SFE-HPLC system (Shimadzu). The ESI-TOF/MS system used was Impact II (Bruker Daltonics). MS was operated in the positive ion mode. The concentrations of abiraterone and abiraterone metabolites, 
including D4A, 3-keto-5 $\alpha$-abiraterone, $3 \alpha-\mathrm{OH}-5 \alpha$-abiraterone, and $3 \beta-\mathrm{OH}-5 \alpha$-abiraterone in the supernatant were measured using the exact mass value of the protonated molecular ion of each compound.

Pharmacokinetic in vivo validation of abiraterone and dutasteride combination. Details of this method have been reported elsewhere (16). Briefly, abiraterone and its metabolite (D4A, 3-keto-5 $\alpha$-abiraterone) were measured before and after combination treatment with abiraterone and dutasteride in a phase II clinical trial in patients with CRPC (UMIN Clinical Trial Registry: UMIN000027795). Pharmacokinetic data in patients who were judged as effective in combination therapy were compared with the data from our in vitro model.

Statistical analysis. All numerical data are presented as the mean \pm standard deviation. Unpaired numerical data were compared using an unpaired Student's t-test (two groups) or analysis of variance (ANOVA; more than two groups). We used Tukey test as the post-hoc test following ANOVA. The synergistic effect of the combination of drugs was calculated using the CompuSyn software (Combosyn Inc.). Statistical analysis was performed using JMP software (Pro.13; SAS Institute, Inc.). P-values were two-sided, and statistical significance was defined as $\mathrm{P}<0.05$, in all tests.

\section{Results}

Bone microenvironment model of prostate cancer with chitosan fiber matrix $3 D$ culture. To demonstrate the bone microenvironment model of prostate cancer, prostate cancer cells and osteoblasts were co-cultured on a microfiber scaffold to examine the characteristics of the co-culture system. We used a microfiber scaffold composed of a three-dimensional chitosan fiber matrix. The scaffold was composed of random fibers with an average diameter of $200 \mathrm{~nm}$. Using a three-dimensional microfiber scaffold, cells may proliferate in a three-dimensional morphology. To recapitulate the bone metastasis microenvironment of castration-resistant prostate cancer, we used C4-2, a cell line of castration-resistant prostate cancer. $\mathrm{C} 4-2$ maintains AR activation and signaling through de novo intratumoral steroidogenesis $(17,18)$. Osteoblasts were differentiated from human mesenchymal stem cells (hMSCs), which were collected from the bone marrow using a special medium. Differentiation of hMSCs into osteoblasts was confirmed by Alizarin red $\mathrm{S}$ staining and alkaline phosphatase staining (Fig. S1). To facilitate separate quantification of $\mathrm{C} 4-2$ and osteoblast cells after co-culture, we stably transfected C4-2 cells with GFP and hMSCs with RFP using lentiviral vectors. We used flow cytometry to determine whether GFP was successfully introduced into C4-2 cells or RFP was introduced into hMSCs (Fig. S2). Fig. 1-A shows the schema of the bone microenvironment model. GFP-transferred C4-2 cells and RFP-transferred osteoblasts differentiated from hMSCs were co-cultured with chitosan fiber matrix $3 \mathrm{D}$ culture. The medium was changed to androgen-free medium $24 \mathrm{~h}$ after starting the co-culture to reflect the bone metastasis environment of castration-resistant prostate cancer. The growth of C4-2 cells and osteoblasts was quantified using a live-cell imaging and analysis system, Cell3 iMager duos (SCREEN). We could non-invasively quantify the static survival of osteoblasts and could maintain a continuous count of C4-2 cells for a maximum of 30 days (Fig. 1B). Fluorescence images at days 15,32 , and 46 showed that $\mathrm{C} 4-2$ grew to form colonies (Fig. 1C). The C4-2 colonies were physically in contact with the osteoblasts. We also examined the effects of co-culturing with osteoblasts. Compared with monoculture, co-culturing with human osteoblasts demonstrated a significant growth enhancement on $\mathrm{C} 4-2$ cells (t-test, $\mathrm{P}<0.01$, day 52), but there was no obvious difference in morphology of the C4-2 cells (Fig. S3).

Drug sensitivity test using bone microenvironment model. We used this model to evaluate the drug sensitivity of androgen receptor-axis-targeted agents (ARATs) and D4A (abiraterone metabolite with AR antagonist). First, we compared the growth curves of the GFP-transfected C4-2 cells (Fig. 2A). Significant difference in growth inhibition was observed from day 18 to day 25 (ANOVA, $\mathrm{P}<0.01$ ), and significant growth inhibition was observed with the addition of enzalutamide (t-test, $\mathrm{P}<0.01)$, apalutamide $(\mathrm{P}<0.01)$, darolutamide $(\mathrm{P}<0.01)$, abiraterone $(\mathrm{P}<0.01)$, or $\mathrm{D} 4 \mathrm{~A}(\mathrm{P}<0.01)$ compared to the control on day 28. Significant differences in growth inhibition were observed among all the investigational agents except between enzalutamide and apalutamide $(\mathrm{P}=0.195)$ and between darolutamide and abiraterone $(\mathrm{P}=0.118)$. Second, we compared the dose-response curves of each investigational agent against C4-2 cells (Fig. 2B). Significant difference in growth inhibition between ARATs was observed at concentrations of $10-100 \mu \mathrm{M}$ (ANOVA, $\mathrm{P}<0.01$ ). The $50 \%$ inhibition concentration $\left(\mathrm{IC}_{50}\right)$ of each drug calculated from the dose-response curve is shown in Table $\mathrm{I}$. The $\mathrm{IC}_{50}$ values of each investigational agent were compared, and significant differences were found among the investigational agents ( $\mathrm{t}$-test, $\mathrm{P}<0.05)$, except between enzalutamide and apalutamide $(\mathrm{P}=0.982)$ and between darolutamide and abiraterone $(\mathrm{P}=0.106)$. The results were similar to the drug effects of the growth curves (Fig. 2A). Next, we compared the drug sensitivity of C4-2 cells with and without co-culture with human osteoblasts in chitosan nanofiber-coated 3D culture plates. Co-culture with human osteoblasts had a inhibitory effect on the growth of all investigational agents on day 28 (Fig. 2C).

Analysis of mRNA and protein expression in C4-2 cells co-cultured with and without osteoblasts. We examined the changes in mRNA and protein expression in C4-2 cells when co-cultured with osteoblasts in this model. Highly purified C4-2 cells were isolated from co-cultured cell suspensions by magnetic-activated cell sorting (MACS ${ }^{\circledR} ;$ Miltenyi Biotec). This was performed using positive selection using specific binding of anti-PSMA antibodies to C4-2 cells. The highly specific separation of C4-2 cells was confirmed by flow cytometry (Fig. S4). We compared the mRNA expression of C4-2 cells isolated from co-culture cell suspensions and monocultured C4-2 cells using RT-PCR (Fig. 3A). We focused on TGF- $\beta$ and EMT-related genes, because accumulating evidence suggests that these molecules play an important role as promoters of tumor cell survival and development in the bone microenvironment. The mRNA expression of TGF- $\beta$ (TGF- $\beta 1$, TGF- $\beta 2$ ) 
A
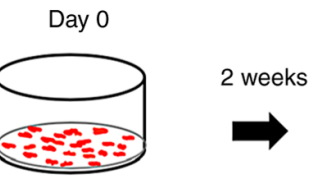

RFP-transfected human-mesenchymal stem cells in osteogenic differentiation medium
Day 14

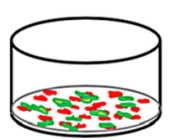

$\uparrow$

Day 15

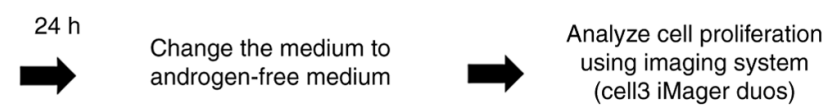

B

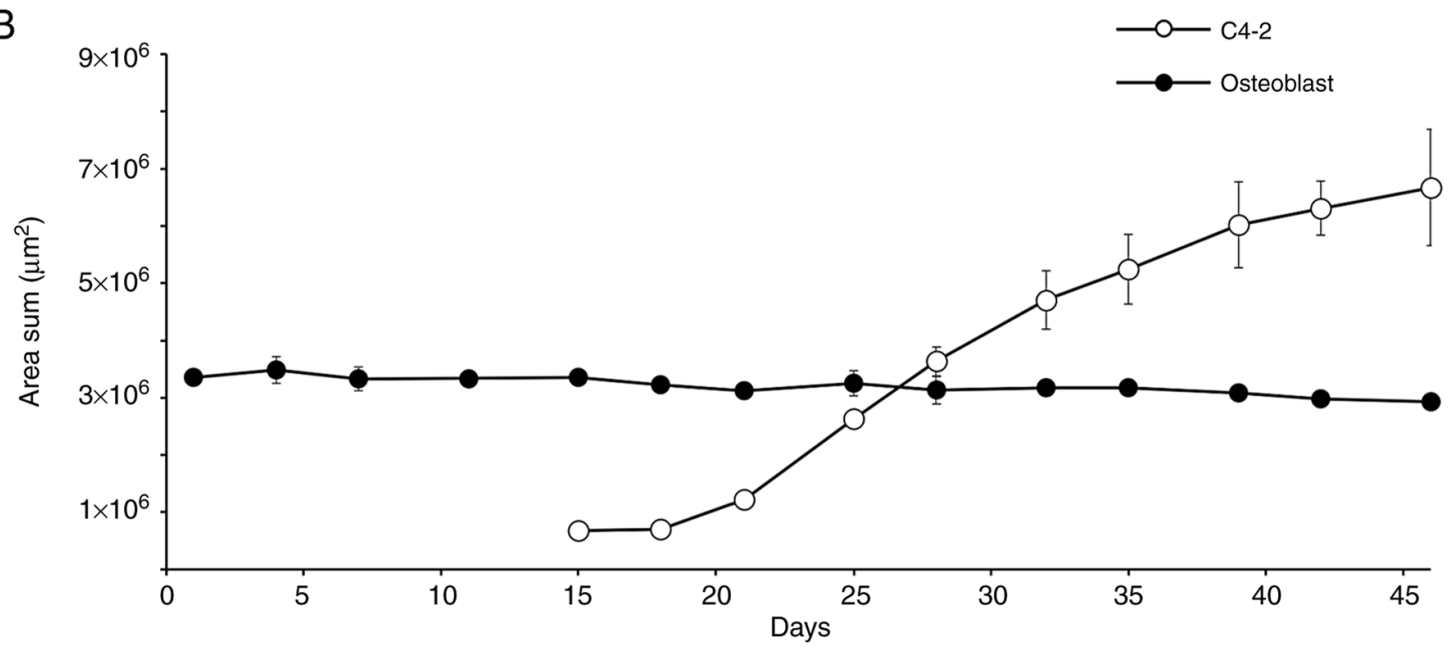

C
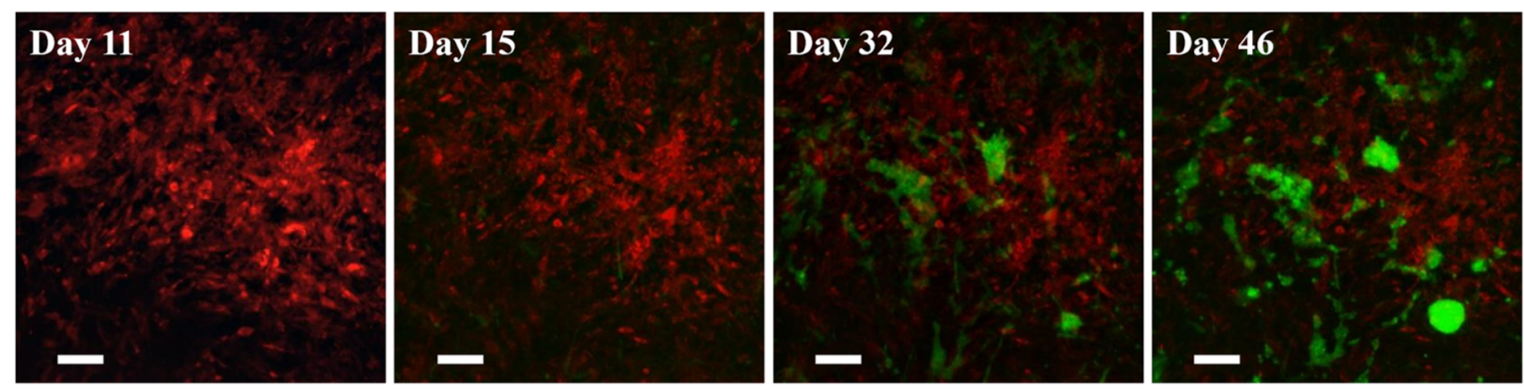

Figure 1. Bone microenvironment model of prostate cancer with chitosan fiber matrix 3D culture. (A) Schema of culture methods, in vitro bone microenvironment model. (B) Growth curve of C4-2 (CRPC cell line) and osteoblast in long term culture. Static survival of osteoblasts and continuous growth of tumor cells (C4-2) were observed under the chitosan nanofiber coated 3D culture. (C) Longitudinal fluorescence image of GFP-transfected C4-2 and red fluorescent protein-transfected osteoblast (green, proliferating C4-2 colonies; red, osteoblasts). Scale bars, $200 \mu \mathrm{m}$. GFP, green fluorescent protein; RFP, red fluorescent protein; CRPC, castration-resistant prostate cancer.

Table I. $\mathrm{IC}_{50}$-values of androgen receptor-axis-targeted agents in the bone microenvironment model.

\begin{tabular}{lc}
\hline Drugs & $\mathrm{IC}_{50}, \mu \mathrm{M}$ \\
\hline Enzalutamide & $50.85 \pm 1.90$ \\
Apalutamide & $51.02 \pm 1.98$ \\
Darolutamide & $35.14 \pm 1.26$ \\
Abiraterone & $38.85 \pm 5.38$ \\
$\Delta 4$ Abiraterone & $10.47 \pm 4.87$ \\
\hline
\end{tabular}

The values are presented as mean \pm SD. Significant differences were found among each investigational agent $(\mathrm{P}<0.05)$ except between enzalutamide and apalutamide $(\mathrm{P}=0.982)$ and between darolutamide and abiraterone $(\mathrm{P}=0.106)$. $\mathrm{IC}_{50}, 50 \%$ inhibition concentration.

was significantly higher in the co-culture than in the monoculture. Similarly, the expression of EMT-related genes (TWIST1,
Snail2, and N-cadherin) was also significantly higher in the co-culture than in the monoculture. The expression of AR and PSA (downstream gene of AR) was significantly higher when co-cultured with osteoblasts. The protein expression of C4-2 cells isolated from co-culture cell suspensions and monoculture was compared by western blotting (Fig. 3B). An identical expression pattern was observed between the mRNA and protein expression of each gene. We also examined the mRNA expression of osteoblast stimulatory factors in the co-culture. mRNA expression of bone morphogenetic protein 2 (BMP2) and vascular endothelial growth factor (VEGF-A, VEGF-B) were significantly higher in the co-culture than in the monoculture (Fig. S5).

Inhibition of tumor growth by combination therapy with abiraterone and dutasteride. We used this model to evaluate the therapeutic effects of the combination of abiraterone and dutasteride in the bone microenvironment. First, we compared the growth curves of GFP-transferred C4-2 cells among 

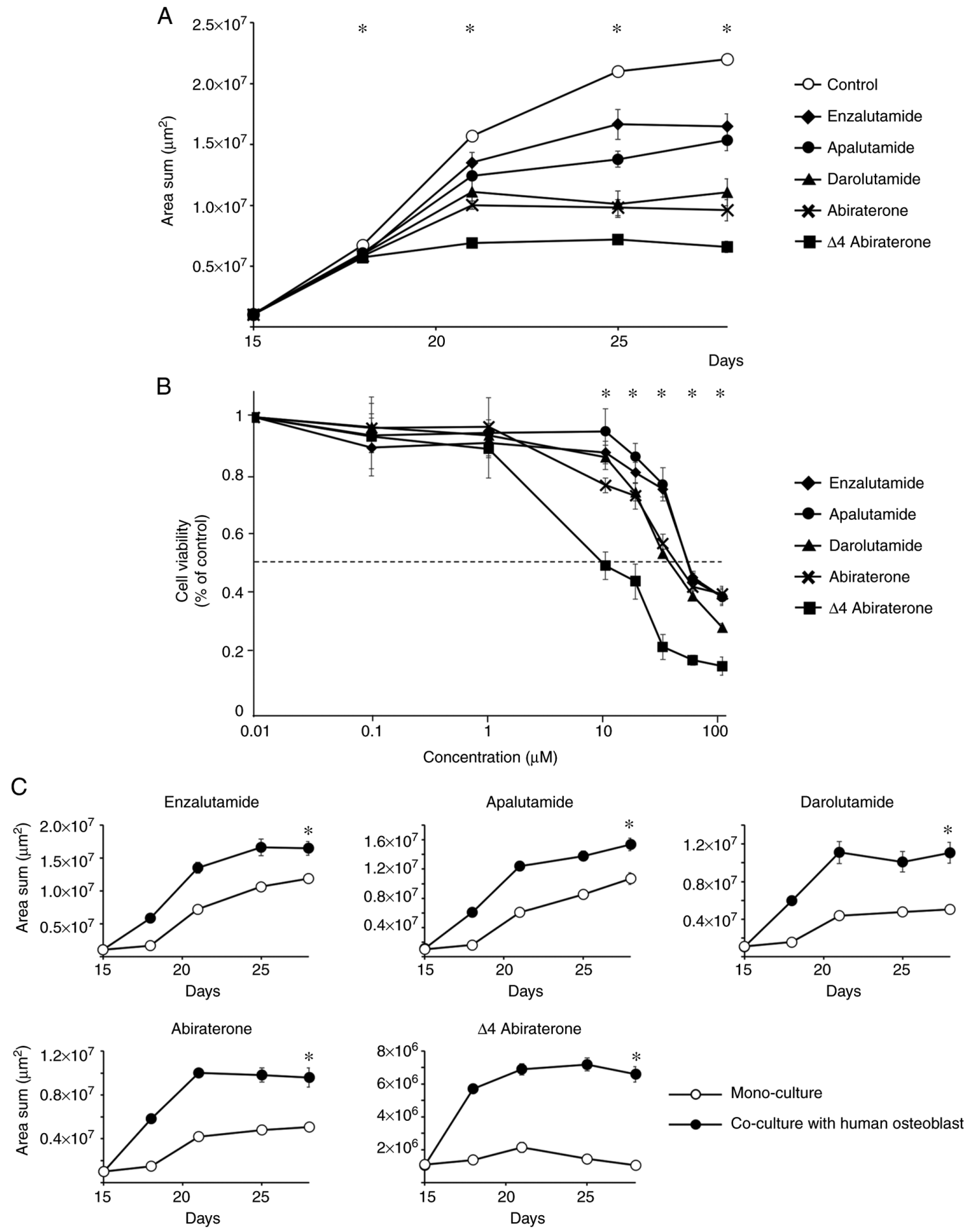

Figure 2. Drug sensitivity test using bone microenvironment model. (A) Drug sensitivity test among ARATs and delta-4 abiraterone (abiraterone metabolite with AR antagonist). Each drug was added to the culture medium at a concentration of $5 \mu \mathrm{M}$ and had dissolved by ethanol on day 15 . Significant overall difference in growth inhibition was observed between all the groups from day 18-25 ("P<0.01). (B) Dose response curve of each drug against C4-2. Significant difference in growth inhibition between ARATs was observed at concentrations of $10-100 \mu \mathrm{M}\left({ }^{*} \mathrm{P}<0.01\right)$. Exposure time, $48 \mathrm{~h}$; baseline drug concentration, $0.01 \mu \mathrm{M}$. (C) Comparison of drug sensitivity for C4-2 with and without co-culture with human osteoblasts in chitosan nanofiber coated 3D culture plate. Co-culture with human osteoblast reduced the growth inhibitory effect of all drugs. " $\mathrm{P}<0.01$, day 28 . ARATs, androgen receptor-axis-targeted agents; AR, androgen receptor.

abiraterone, dutasteride, and both combinations (Fig. 4A). The combination of abiraterone and dutasteride had a greater colony inhibitory effect on tumor growth (ANOVA, $\mathrm{P}<0.01$, day 46). Second, we compared the dose-response curves of each investigational agent against C4-2 cells (Fig. 4B). To examine whether this effect was additive or synergistic, dose-dependent effects with constant ratio design and combination index (CI) values were calculated according to the Chou and Talalay median effect principal (14). Dutasteride synergistically enhanced the inhibitory effect of abiraterone on the colony growth of C4-2 cells (Fig. 4C). We then examined the concentrations of abiraterone metabolites in C4-2 cells treated with abiraterone alone or abiraterone and dutasteride. C4-2 cells were isolated from cell suspensions 
A

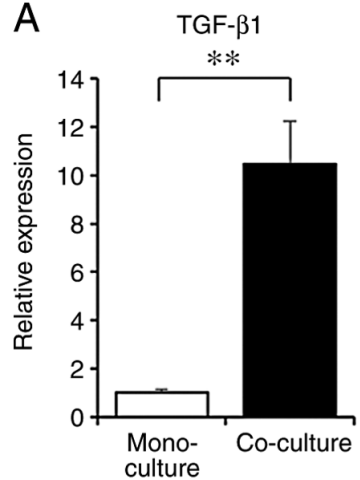

TWIST1

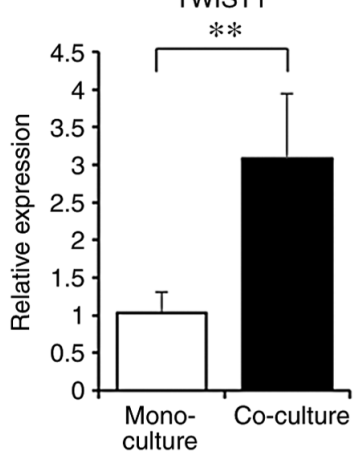

E-cadherin

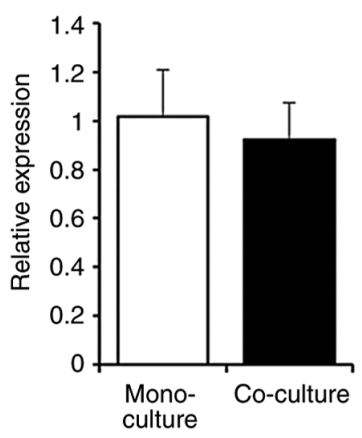

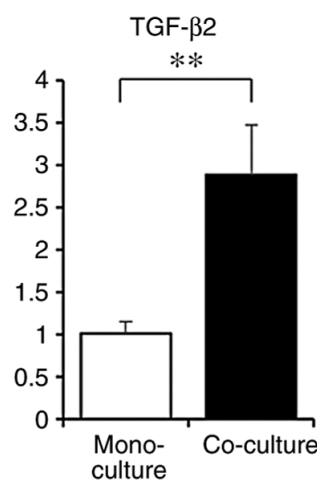

Snail1

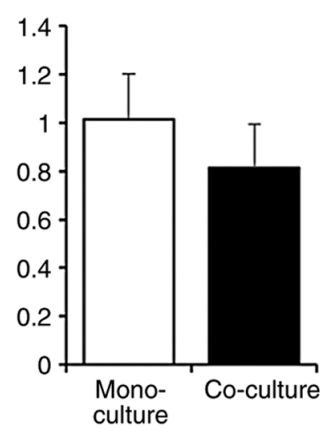

$\mathrm{N}$-cadherin

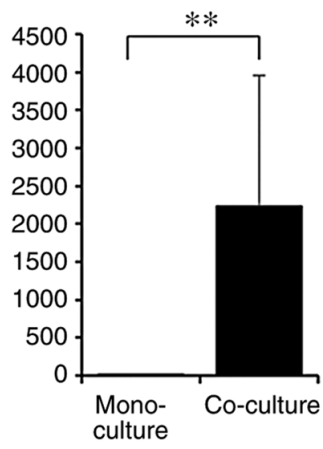

TGF- $\beta 3$
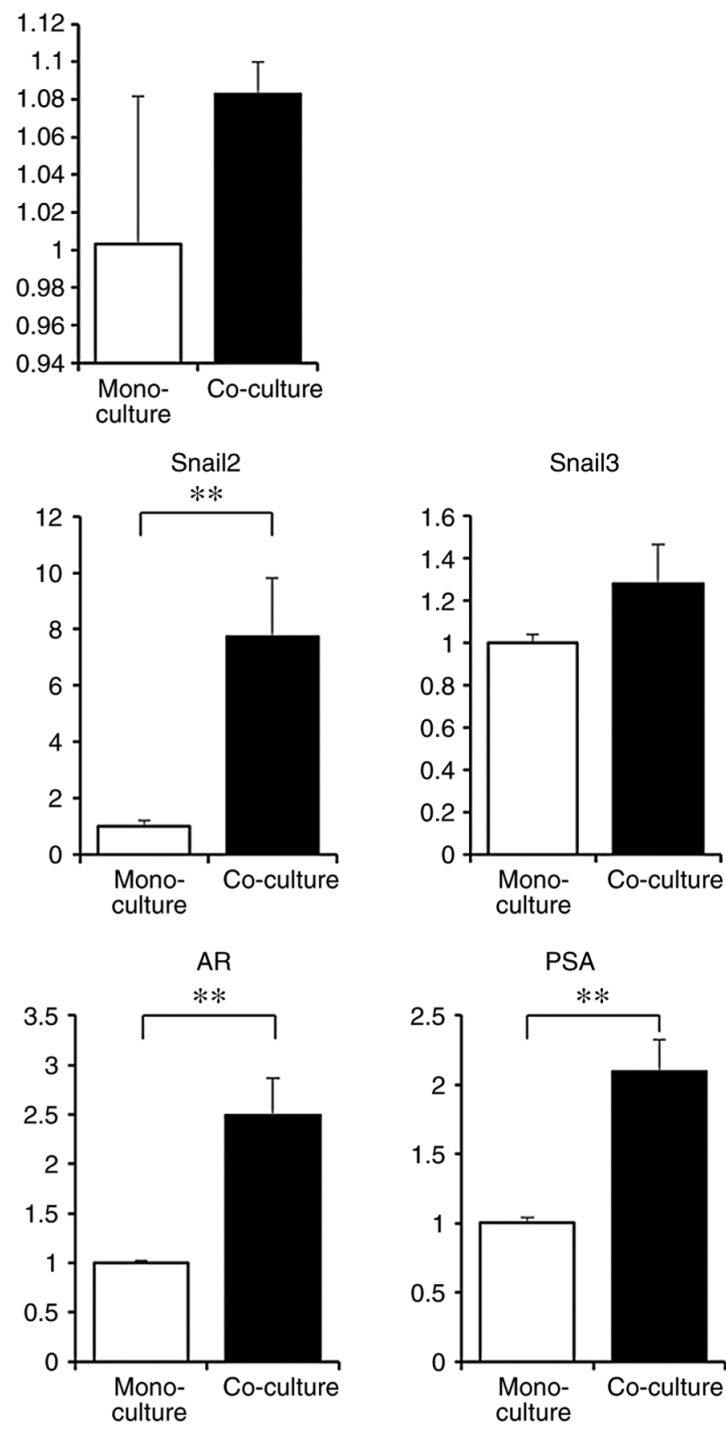

B

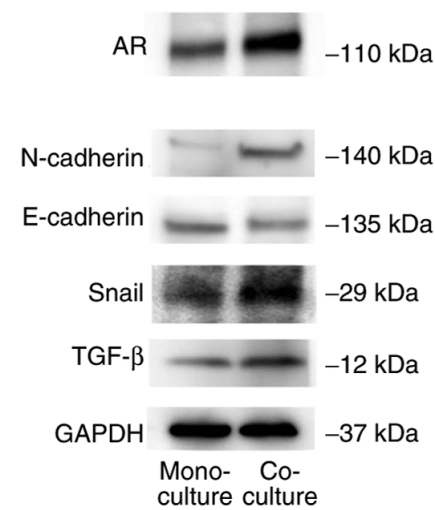

Figure 3. Analysis of EMT- and AR-related gene expressions and protein expressions in C4-2 cells co-cultured with and without osteoblasts. (A) mRNA expression of the EMT-related genes (TGF- $\beta 1$, TGF- $\beta 2$, TWIST1, Snail 2 and N-cadherin) was significantly higher in the co-culture than that in the monoculture. AR and PSA (downstream gene of AR) were statistically higher in cells co-cultured with osteoblasts. Each mRNA level was analyzed using reverse transcription-quantitative PCR. (B) Analysis of EMT-related protein expression levels in C4-2 cells co-cultured with and without osteoblast by western blotting. Identical expression pattern was observed between mRNA and protein of each gene. ${ }^{* *} \mathrm{P}<0.01$. EMT, epithelial-mesenchymal transition; AR, androgen receptor; TWIST1, twist-related protein 1; PSA, prostate-specific antigen.

on days 17 and 28 ( 2 and 13 days after drug addition). C4-2 cells were lysed with acetonitrile, and the supernatants were analyzed using LC-ESI-TOF/MS. The concentrations of each investigational agent used are listed in Table II. On day 17, the combination of dutasteride significantly decreased the concentration of 3-keto-5 $\alpha$-abiraterone (t-test, $\mathrm{P}<0.05)$ and $3 \beta-\mathrm{OH}-5 \alpha$-abiraterone $(\mathrm{P}<0.01)$. On day 28 , the combination of dutasteride tended to decrease the concentration of 

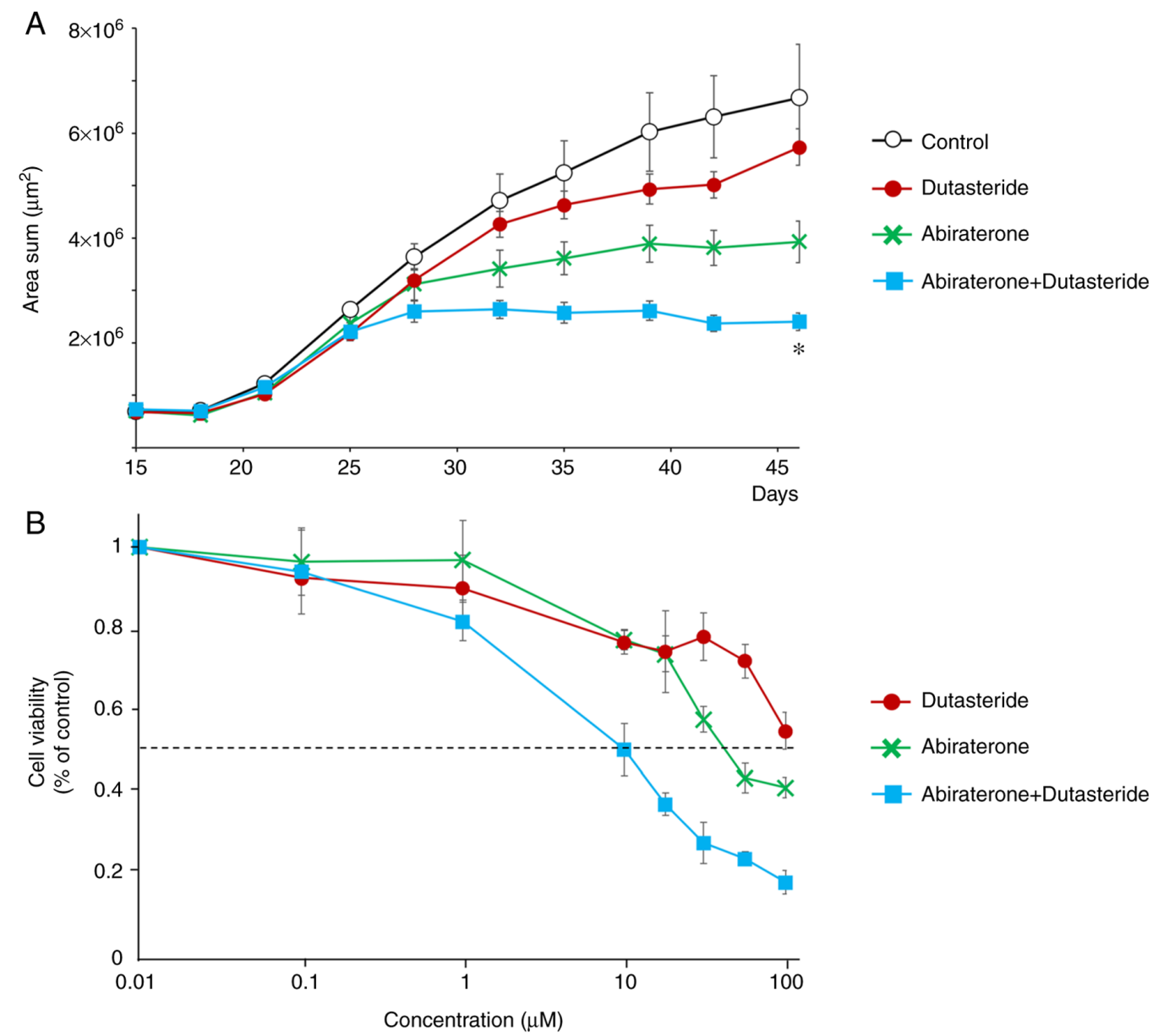

C
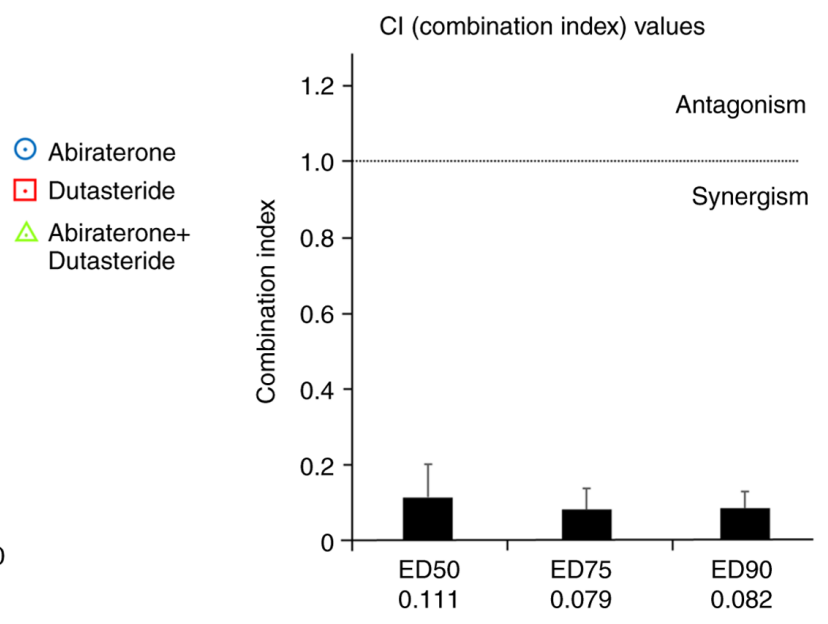

Figure 4. Inhibition of tumor growth by the combination of abiraterone and dutasteride. (A) Comparison of longitudinal colony inhibition of C4-2 among abiraterone, dutasteride and a combination of both. Each drug was added to culture medium at a concentration of $5 \mu \mathrm{M}$ and dissolved by ethanol on day 15 . A combination of abiraterone and dutasteride had a potent inhibitory effect on tumor growth $\left({ }^{*} \mathrm{P}<0.01\right.$, day 46$)$. (B) Dose-response curve of abiraterone, dutasteride and their combination against C4-2. Drug exposure time, $48 \mathrm{~h}$; baseline drug concentration, $0.01 \mu \mathrm{M}$ of each drug. Results were similar with the drug effect of growth curves. (C) Synergistic effect of the combination of abiraterone and dutasteride on tumor growth inhibition. Dose-dependent effects and CI values were calculated using CompuSyn software. Drug exposure time, $48 \mathrm{~h}$.

3-keto-5 $\alpha$-abiraterone $(\mathrm{P}=0.06)$ and a significant decrease in $3 \beta-\mathrm{OH}-5 \alpha$-abiraterone $(\mathrm{P}<0.01)$. These results suggest that the combination of abiraterone and dutasteride had a more potent inhibitory effect on tumor growth by reducing the androgen receptor agonist activity of $5 \alpha$-abiraterone. In a phase II study of abiraterone and dutasteride combination therapy in CRPC patients (16), effective cases where PSA was decreased by the combined use of abiraterone and dutasteride showed a decrease in serum 3-keto-5 $\alpha$-abiraterone concentration (Fig. S6), similar to the results of the microenvironmental model using the chitosan culture substrate.

\section{Discussion}

Recently, in vitro culture models using biomimetic nanofiber scaffolds have been reported $(19,20)$. Compared with 
Table II. Intracellular concentrations of abiraterone and each metabolite.

A, Day 17

\begin{tabular}{lccc}
\hline Metabolite & Abiraterone & Abiraterone + Dutasteride & P-value \\
\hline Abiraterone, $\mathrm{ng} / \mathrm{ml}$ & $346.60 \pm 68.99$ & $351.73 \pm 48.41$ & $\mathrm{NS}$ \\
$\Delta 4$ Abiraterone, $\mathrm{ng} / \mathrm{ml}$ & $4.54 \pm 1.14$ & $3.08 \pm 0.38$ & $\mathrm{NS}$ \\
3-keto-5 $\alpha$-Abiraterone, $\mathrm{ng} / \mathrm{ml}$ & $3.24 \pm 0.91$ & $0.91 \pm 0.73$ & 0.01 \\
$3 \beta$-OH-5 $\alpha$-Abiraterone, $\mathrm{ng} / \mathrm{ml}$ & $8.63 \pm 0.43$ & $0.99 \pm 0.73$ & $<0.01$ \\
\hline
\end{tabular}

B, Day 28

\begin{tabular}{lccc}
\hline Metabolite & Abiraterone & Abiraterone + Dutasteride & P-value \\
\hline Abiraterone, $\mathrm{ng} / \mathrm{ml}$ & $1,228.76 \pm 81.91$ & $2,125.07 \pm 145.86$ & $<0.01$ \\
$\Delta 4$ Abiraterone, $\mathrm{ng} / \mathrm{ml}$ & $8.04 \pm 1.71$ & $7.20 \pm 0.15$ & $\mathrm{NS}$ \\
3-keto-5 $\alpha$-Abiraterone, $\mathrm{ng} / \mathrm{ml}$ & $2.97 \pm 0.81$ & $1.73 \pm 0.77$ & 0.06 \\
$3 \beta$-OH-5 $\alpha$-Abiraterone, $\mathrm{ng} / \mathrm{ml}$ & $24.90 \pm 1.86$ & $2.20 \pm 0.63$ & $<0.01$ \\
\hline
\end{tabular}

The values are presented as mean \pm SD. NS, Not Significant.

cells cultured on polystyrene culture dishes, cells cultured on three-dimensional culture scaffolds formed colonies and maintained their morphology and functions similar to living organisms for a long time. In terms of the bone environment, chitosan nanofibers have attracted attention as a novel scaffold for the repair and regeneration of bone tissue. Long-term culture of osteoblasts using chitosan nanofiber scaffolds has been reported to promote osteoblast propagation and maturation by regulating osteoblast-related osteopontin, osteocalcin, and alkaline phosphatase expression via runt-related transcription factor 2 (21). We hypothesized that co-cultured osteoblasts and prostate cancer cells on chitosan nanofiber scaffolds would enable long-term culture under conditions similar to those of living organisms.

The bone microenvironment is important for research, given that bone metastases reflect the clinical picture of advanced prostate cancer and form a major cause of disease morbidity. Metastasis of prostate cancer cells to bone is a multi-step process that involves detachment of cancer cells from the primary site, migration of cells in the blood or lymph, attachment to bone tissue, and development of tumors at the site of bone metastasis. The interaction between prostate cancer cells and osteoblasts is essential for bone metastasis $(22,23)$. Prostate cancer cells preferentially migrate to osteoblast-rich areas of the bone $(24,25)$. The physical contact between prostate cancer cells and osteoblasts in bone destroys bone structure in the presence of osteoclasts and develops a mutually enhanced growth cycle of prostate cancer cells and osteoblasts (26). Excretion of numerous molecular factors from bone-residing cells further promotes cancer cell survival and metastatic progress. This phenomenon is known as the 'feed forward cycle' or 'vicious cycle' where transforming growth factor- $\beta$ (TGF- $\beta$ ) plays an essential role as promoter of tumor cell survival and development in the bone microenvironment (27). TGF- $\beta$ signaling is a double-edged sword in cancer. In the early stages of tumorigenesis, TGF- $\beta$ signaling acts as a tumor suppressor, while in advanced stages, it promotes epithelial-to-mesenchymal transition (EMT), invasion, and metastatic potential (25). TGF- $\beta$ expressed in the tumor microenvironment also affects other cell types, including immune cells and endothelial cells, causing immune suppression and angiogenesis and promoting metastatic dissemination of tumor cells (28).

In the present study, we established a novel microenvironment model that mimics the bone microenvironment of CRPC, which reflects the bone microenvironment of mCRPC. The expression of TGF- $\beta$ was enhanced and promoted EMT in C4-2 cells co-cultured with osteoblasts. This is supported by previous reports $(29,30)$ and demonstrates the validity of our model. Increased expression of TGF- $\beta$ increases the viability of C4-2 cells, which is related to drug resistance $(31,32)$. Co-culture with osteoblasts demonstrated increased expression of AR and its downstream gene, PSA. TGF- $\beta$ is involved in the upregulation of $\mathrm{AR}$ and the acquisition of castration resistance (33), which may be responsible for the difference in resistance to ARATs by co-culture and sensitivity in drug sensitivity testing. In addition, co-culture with osteoblasts showed increased expression of osteoblast stimulatory factors, bone morphogenetic protein 2 (BMP2), and vascular endothelial growth factor (VEGF-A, VEGF-B) (34). These results suggest that our model may be useful for understanding the molecular mechanisms of interaction between prostate cancer cells and osteoblasts and for the detection of new molecular targets for the treatment of bone metastasis. We aimed to stablish in vitro drug sensitivity testing for new ARATs which were testified to be effective in non-metastatic CRPC patients. These patients are likely to harbor bone micrometastasis. The gene expression profile in our model suggest early phase may be representative of bone micrometastasis, and late phase may represent clinical bone metastases. Therefore, our model may include both non-metastatic and metastatic CRPC. In addition, the combination of abiraterone and dutasteride had a synergistic effect on the colony growth of C4-2 cells 
in the microenvironment model. This could be attributed to the reduction of 3-keto-5 $\alpha$-abiraterone which acts as an AR agonist. These results provide evidence that the combination of abiraterone and dutasteride may be a clinically more potent treatment for prostate cancer than the other ARATs. The consistent phenomenon that the concentration of 3-keto-5 $\alpha$-abiraterone decreased with the combination of abiraterone and dutasteride both from effective cases in phase II trials and from our model using C4-2, means that this model may be valuable for the assessment of the bone microenvironment in CRPC.

Regarding the previous in vitro model using chitosan as a $3 \mathrm{D}$ substrate, a few publications have reported the benefit of chitosan in combination with chondroitin acid or alginate (35-37). Neither chondroitin acid nor alginate was used in this model. However, these reports indicate that cells form colonies and grow using scaffolds. We also observed the induction of EMT by co-culturing osteoblasts and tumor cells in the absence of chondroitin acid. The advantage of our model is the co-culture of osteoblasts.

Recently, patient-specific models of solid tumors using 3D cultures of spheroids and organoids from tumor cells or biopsies have received much attention $(38,39)$. Organoids derived from patient tissue have been used for in vitro screening of drug responsiveness prior to treatment to determine treatment strategies and predict efficacy. In future studies, patient-specific $3 \mathrm{D}$ models co-cultured with organoids from patient prostate cancer tissue with osteoblasts using a chitosan fiber matrix may contribute to tailored medicine.

A limitation of this model is that it does not include osteoclasts, which are important factors in the bone microenvironment. Osteoclasts in bone destroy bone structure and develop a mutually enhanced growth cycle of prostate cancer cells and osteoblasts. Since bone metastases of prostate cancer are characterized as osteogenic rather than osteolytic, the lack of osteoclasts may not be so important for this model. Establishing mineralization by cancer cells should be the next challenge in future studies. The other limitation of this in vitro study is the lack of in vivo study. The mouse model of bone metastasis using prostate cancer cells has been reported (40), and we would like to eventually investigate the results of this study using a mouse model. The other limitation of this model is that it only uses C4-2 cells as the prostate cancer cell line. This is because it was necessary to use a cell line to maintain AR activation and signaling through de novo intratumoral steroidogenesis to mimic the bone microenvironment of CRPC. Validation using several other CRPC cell lines, or patient-derived cells (organoids) is needed in future studies.

\section{Acknowledgements}

The authors would like to thank Ms Shizuka Ishii and Ms Kiyomi Fujita (Department of Urology, Graduate School of Medicine, Yamaguchi University, Ube, Yamaguchi, Japan) for their technical support.

\section{Funding}

The present study was supported by a Grant-in-Aid for Scientific Research Foundation B (KAKENHI) from the Japan
Society for the Promotion of Science (grant nos. 17H04330 and B20H03806) and the Jansen Pharma non-clinical investigator-initiated study (grant no. ARN-I-17-JPN-001-V01).

\section{Availability of data and materials}

The datasets used and/or analyzed during the current study are available from the corresponding author on reasonable request.

\section{Authors' contributions}

MS, MidM, MirM, HH, KU, SO, JM, RI, SY, YY and JH contributed to the conception and design of this study. HirM, $\mathrm{HH}, \mathrm{KU}, \mathrm{JM}$ and KT performed the experiments. HidM supervised the study and contributed to manuscript writing. All authors have read and approved the final manuscript. HidM and $\mathrm{HH}$ confirm the authenticity of all the raw data.

\section{Ethics approval and consent to participate}

Not applicable.

\section{Patient consent for publication}

Not applicable.

\section{Competing interests}

Koji Tamada holds stocks in and receives remuneration from Noile-Immune Biotech Inc., and received lecture fees from Ono Pharmaceutical, MSD, AstraZeneca, Eli Lilly Japan and Chugai Pharmaceutical. Hideyasu Matsuyama received funding from Janssen Pharmaceutical. The other authors declare that they have no competing interests.

\section{References}

1. Bray F, Ferlay J, Soerjomataram I, Siegel RL, Torre LA and Jemal A: Global cancer statistics 2018: GLOBOCAN estimates of incidence and mortality worldwide for 36 cancers in 185 countries. CA Cancer J Clin 68: 394-424, 2018.

2. Hamdy FC, Donovan JL, Lane JA, Mason M, Metcalfe C, Holding P, Davis M, Peters TJ, Turner EL, Martin RM, et al: 10-Year outcomes after monitoring, surgery, or radiotherapy for localized prostate cancer. N Engl J Med 375: 1415-1424, 2016.

3. Weckermann D, Polzer B, Ragg T, Blana A, Schlimok G, Arnholdt H, Bertz S, Harzmann R and Klein CA: Perioperative activation of disseminated tumor cells in bone marrow of patients with prostate cancer. J Clin Oncol 27: 1549-1556, 2009.

4. National Cancer Institute. SEER Cancer Stat Facts: Prostate Cancer, 2020. Available from: http://seer.cancer.gov/statfacts/html/prost.html. Accessed November 14, 2020.

5. Sweeney CJ, Chen YH, Carducci M, Liu G, Jarrard DF, Eisenberger M, Wong YN, Hahn N, Kohli M, Cooney MM, et al: Chemohormonal therapy in metastatic hormone-sensitive prostate cancer. N Engl J Med 373: 737-746, 2015.

6. Wadosky KM and Koochekpour S: Molecular mechanisms underlying resistance to androgen deprivation therapy in prostate cancer. Oncotarget 7: 64447-64470, 2016.

7. Sumanasuriya S and Bono JD: Treatment of advanced prostate cancer-A review of current therapies and future promise. Cold Spring Harb Perspect Med 8: a030635, 2018.

8. Pezaro C, Omlin A, Lorente D, Rodrigues DN, Ferraldeschi R, Bianchini D, Mukherji D, Riisnaes R, Altavilla A, Crespo M, et al: Visceral disease in castration-resistant prostate cancer. Eur Urol 65: 270-273, 2014. 
9. Shiirevnyamba A, Takahashi T, Shan H, Ogawa H, Yano S, Kanayama H, Izumi K and Uehara H: Enhancement of osteoclastogenic activity in osteolytic prostate cancer cells by physical contact with osteoblasts. Br J Cancer 104: 505-513, 2011.

10. Antunes J, Gaspar VM, Ferreira L, Monteiro M, Henrique R, Jerónimo C and Mano JF: In-air production of 3D co-culture tumor spheroid hydrogels for expedited drug screening. Acta Biomater 94: 392-409, 2019.

11. Ryan CJ, Smith MR, Fizazi K, Saad F, Mulders PF, Sternberg CN, Miller K, Logothetis CJ, Shore ND, Small EJ, et al: Abiraterone acetate plus prednisone versus placebo plus prednisone in chemotherapy-naive men with metastatic castration-resistant prostate cancer (COU-AA-302): Final overall survival analysis of a randomised, double-blind, placebo-controlled phase 3 study. Lancet Oncol 16: 152-160, 2015.

12. Li Z, Alyamani M, Li J, Rogacki K, Abazeed M, Upadhyay SK, Balk SP, Taplin ME, Auchus RJ and Sharifi N: Redirecting abiraterone metabolism to fine-tune prostate cancer anti-androgen therapy. Nature 533: 547-551, 2016.

13. Andriole GL, Bostwick DG, Brawley OW, Gomella LG, Marberger M, Montorsi F, Pettaway CA, Tammela TL, Teloken C, Tindall DJ, et al: Effect of dutasteride on the risk of prostate cancer. N Engl J Med 362: 1192-1202, 2010.

14. Chou TC and Talalay P: Quantitative analysis of dose-effect relationships: The combined effects of multiple drugs or enzyme inhibitors. Adv Enzyme Regul 22: 27-55, 1984.

15. Livak KJ and Schmittgen TD: Analysis of relative gene expression data using real-time quantitative PCR and the 2(-Delta Delta C(T)) method. Methods 25: 402-408, 2001.

16. Matsuyama H, Shiota M, Tashiro K, Kanji H, Horiyama S, Eto M, Egawa S, Haginaka J and Inoue R: Phase II study of the efficacy of abiraterone acetate with dutasteride for castration resistant prostate cancer. J Clin Oncol 39: 112-112, 2021.

17. Horoszewicz JS, Leong SS, Kawinski E, Karr JP, Rosenthal H, Chu TM, Mirand EA and Murphy GP: LNCaP model of human prostatic carcinoma. Cancer Res 43: 1809-1818, 1983.

18. Cai C, Chen S, Ng P, Bubley GJ, Nelson PS, Mostaghel EA, Marck B, Matsumoto AM, Simon NI, Wang H, et al: Intratumoral de novo steroid synthesis activates androgen receptor in castration-resistant prostate cancer and is upregulated by treatment with CYP17A1 inhibitors. Cancer Res 71: 6503-6513, 2011.

19. Rajendran D, Hussain A, Yip D, Parekh A, Shrirao A and Cho CH: Long-term liver-specific functions of hepatocytes in electrospun chitosan nanofiber scaffolds coated with fibronectin. J Biomed Mater Res A 105: 2119-2128, 2017.

20. Hussain A, Collins G, Yip D and Cho CH: Functional 3-D cardiac co-culture model using bioactive chitosan nanofiber scaffolds. Biotechnol Bioeng 110: 637-647, 2013.

21. Ho MH, Liao MH, Lin YL, Lai CH, Lin PI and Chen RM Improving effects of chitosan nanofiber scaffolds on osteoblast proliferation and maturation. Int J Nanomedicine 9: 4293-4304, 2014.

22. Kimura Y, Matsugaki A, Sekita A and Nakano T: Alteration of osteoblast arrangement via direct attack by cancer cells: New insights into bone metastasis. Sci Rep 7: 44824, 2017.

23. Kingsley LA, Fournier PG, Chirgwin JM and Guise TA: Molecular biology of bone metastasis. Mol Cancer Ther 6 : 2609-2617, 2007.

24. Wang N, Docherty FE, Brown HK, Reeves KJ, Fowles AC, Ottewell PD, Dear TN, Holen I, Croucher PI and Eaton CL: Prostate cancer cells preferentially home to osteoblast-rich areas in the early stages of bone metastasis: Evidence from in vivo models. J Bone Miner Res 29: 2688-2696, 2014.

25. Klein CA: Selection and adaptation during metastatic cancer progression. Nature 501: 365-372, 2013.
26. Guise TA, Mohammad KS, Clines G, Stebbins EG, Wong DH, Higgins LS, Vessella R, Corey E, Padalecki S, Suva L and Chirgwin JM: Basic mechanisms responsible for osteolytic and osteoblastic bone metastases. Clin Cancer Res 12 (Suppl 1): 6213S-6216S, 2006.

27. Weilbaecher KN, Guise TA and McCauley LK: Cancer to bone: A fatal attraction. Nat Rev Cancer 11: 411-425, 2011.

28. Chiechi A, Waning DL, Stayrook KR, Buijs JT, Guise TA and Mohammad KS: Role of TGF- $\beta$ in breast cancer bone metastases. Adv Biosci Biotechnol 4: 15-30, 2013.

29. Pickup M, Novitskiy S and Moses HL: The roles of TGF $\beta$ in the tumour microenvironment. Nat Rev Cancer 13: 788-799, 2013.

30. Juárez $\mathrm{P}$ and Guise TA: TGF- $\beta$ in cancer and bone: Implications for treatment of bone metastases. Bone 48: 23-29, 2011.

31. Montanari M, Rossetti S, Cavaliere C, D'Aniello C, Malzone MG, Vanacore D, Di Franco R, La Mantia E, Iovane G, Piscitelli R, et al: Epithelial-mesenchymal transition in prostate cancer: An overview. Oncotarget 8: 35376-35389, 2017.

32. NakazawaMandKyprianou N:Epithelial-mesenchymal-transition regulators in prostate cancer: Androgens and beyond. J Steroid Biochem Mol Biol 166: 84-90, 2017.

33. Shiota M, Itsumi M, Takeuchi A, Imada K, Yokomizo A, Kuruma H, Inokuchi J, Tatsugami K, Uchiumi T, Oda Y and Naito S: Crosstalk between epithelial-mesenchymal transition and castration resistance mediated by Twist1/AR signaling in prostate cancer. Endocr Relat Cancer 22: 889-900, 2015.

34. Fizazi K, Yang J, Peleg S, Sikes CR, Kreimann EL, Daliani D, Olive M, Raymond KA, Janus TJ, Logothetis CJ, et al: Prostate cancer cells-osteoblast interaction shifts expression of growth/survival-related genes in prostate cancer and reduces expression of osteoprotegerin in osteoblasts. Clin Cancer Res 9: 2587-2597, 2003

35. Xu K, Wang Z, Copland JA, Chakrabarti R and Florczyk SJ: 3D porous chitosan-chondroitin sulfate scaffolds promote epithelial to mesenchymal transition in prostate cancer cells. Biomaterials 254: 120126, 2020.

36. Xu K, Ganapathy K, Andl T, Wang Z, Copland JA, Chakrabarti R and Florczyk SJ: 3D porous chitosan-alginate scaffold stiffness promotes differential responses in prostate cancer cell lines. Biomaterials 217: 119311, 2019.

37. Wang K, Kievit FM, Florczyk SJ, Stephen ZR and Zhang M: 3D porous chitosan-alginate scaffolds as an in vitro model for evaluating nanoparticle-mediated tumor targeting and gene delivery to prostate cancer. Biomacromolecules 16: 3362-3372, 2015.

38. Elbadawy M, Abugomaa A, Yamawaki H, Usui T and Sasaki K: Development of prostate cancer organoid culture models in basic medicine and translational research. Cancers (Basel) 12: 777, 2020.

39. Bartucci M, Ferrari AC, Kim IY, Ploss A, Yarmush M and Sabaawy HE: Personalized medicine approaches in prostate cancer employing patient derived 3D organoids and humanized mice. Front Cell Dev Biol 4: 64, 2016.

40. Kuchimaru T, Kataoka N, Nakagawa K, Isozaki T, Miyabara H, Minegishi M, Kadonosono T and Kizaka-Kondoh S: A reliable murine model of bone metastasis by injecting cancer cells through caudal arteries. Nat Commun 30: 2981, 2018.

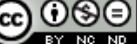

This work is licensed under a Creative Commons Attribution-NonCommercial-NoDerivatives 4.0 International (CC BY-NC-ND 4.0) License. 